\section{Signal value and physiological response to affective visual stimuli*}

\author{
DOUGLAS CARROLL \\ Australian National University, A.C.T. 2601, Australia
}

Forehead pulse amplitude and GSR were monitored while Ss viewed a set of affective and neutral slides under two conditions. In one condition, signal value was minimized, in the other it was maximized. The forehead pulse amplitude response was influenced by signal value change. Both GSR and self-report of affect appeared insensitive to changes in signal value.

Carroll $^{1}$ found that unpleasant visual stimuli elicited physiological responses such as forehead vasoconstriction and a relatively slow habituating galvanic skin response (GSR), indicative of the defense reaction (DR) as described by Sokolov (1963). With visual stimuli of a pleasant, interesting, or boring nature, forehead vasodilation and relatively rapid habituating GSRs, indicative of orienting reactions (ORs), were observed. These findings contradict those of Hare, Wood, Britain, \& Shadman (1970), who observed predominantly ORs to unpleasant homicide slides.

One explanation of the discrepancy between the two studies involves the notion of signal value. According to Sokolov (1963), signal value can be imposed on a stimulus by making the stimulus a conditioned stimulus or by using verbal instructions to confer some additional or alternative interpretation on the stimulus. Signal value investment would appear to decrease the probability of obtaining a DR and maximize conditions for the appearance of the OR. Campos \& Johnson (1967) found that cardiac acceleration, a presumed component of the DR (Graham \& Clifton, 1966), accompanied presentation of road accident slides. When instructions for later verbalization were introduced, cardiac deceleration, indicative of the OR, was observed. It appears, then, that the presence or absence of signal value is critical to the physiological responses obtained in such situations.

Carroll ${ }^{1}$ made a formal attempt to minimize signal value by stressing that the task was purely one of looking at the slides. Hare et al (1970) apparently did not give such instructions. Orne (1962) pointed out that, if not given explicit expectancies of what is demanded of them in a psychological experiment, individuals will manufacture their own hypotheses about the task and presumably convey

*I am grateful to Protessor K. A. Provins and Dr. W. P. Bellingham for their critical advice during the design of this experiment. their own signal values on the stimuli. It is probable, then, that the two studies were not equivalent with regard to the signal value invested in them.

The present experiment examines the physiological responses elicited by affective and neutral visual stimuli under two conditions. One condition attempts to maximize signal value, the other to minimize it.

\section{SUBJECTS}

The Ss were 24 male students. Twelve Ss were assigned randomly to the signal group, 12 to the nonsignal group.

\section{STMULII}

Twenty undergraduates $(10$ males and 10 females) from the same population as the experimental Ss rated 60 slides on two 7-point rating scales, one of "pleasantness" ( 1 = very unpleasant, $7=$ very pleasant) and the other of "interest" ( $1=$ very interesting, 7 = very boring). From these ratings four blocks of slides were chosen: an unpleasant block (U), a pleasant block (P), an interesting block (I), and a boring block (B). Table 1 indicates the mean ratings for each block on the two scales. Each block contained six slides. The slides were projected onto a screen about $8 \mathrm{ft}$ from $S$. Image size was approximately $2 \times 3 \mathrm{ft}$.

\section{DESIGN}

The slides were shown in blocks. All Ss saw all four slide blocks. The design is similar to that used by Campos \& Johnson (1967). Each slide within a block was shown for $20 \mathrm{sec}$, making the total presentation time for a block $2 \mathrm{~min}$. The interblock interval was
2 min. Of the 24 possible orders of block presentations, 12 were selected. One signal and one nonsignal $S$ saw each of the 12 orders. Within a block the order of the slides remained constant throughout the experiment. APPARATUS

A Grass Model 7 polygraph was used to record forehead pulse amplitude (PA) and GSR.

A photoelectric transducer, consisting of a Phillips ORP 12 cadmium sulphide photoconductive cell and an Albrecht Alba Type 10 (6-V, 50-mA) lamp embedded in black phenolic phastic, was used to measure PA. The plastic was concave to fit neatly onto the forehead. A fine band of soft elastic held the transducer in place, and zinc oxide tape was applied to prevent movement artifacts. A dark headband was used to shield the transducer from ambient light changes. Signals from the transducer were fed into the PC input of a Grass 7P8B preamplifier. A time constant of $0.5 \mathrm{sec}$ was used.

A Grass 7P1A preamplifier, set in the P.G.R. input position, was used to record GSR. Ag/AgCl electrodes $(3.2 \mathrm{~cm}$ in diam) were applied to the palm of each hand with Nikkoh Kirokushi electrode paste.

Slides were presented by a Kodak Carousel $\mathbf{S}$ projector.

Table 1

Mean Ratings for Each of the Four Stimulus Blocks on the Two 7-Point Scales

\begin{tabular}{lcc}
\hline Stimulus Block & $\begin{array}{c}\text { Unpleasant- } \\
\text { Pleasant }\end{array}$ & $\begin{array}{c}\text { Interesting- } \\
\text { Boring }\end{array}$ \\
\hline Unpleasant (C) & $\mathbf{1 . 8 2}$ & $\mathbf{2 . 6 2}$ \\
Pleasant (P) & 5.33 & 2.52 \\
Interesting (I) & $\mathbf{4 . 3 0}$ & 2.45 \\
Boring (B) & $\mathbf{4 . 0 4}$ & 5.29 \\
\hline
\end{tabular}

\section{PROCEDURE}

The $S$ was seated in a comfortable armchair in a sound-attenuated temperature-controlled room.

Two self-report measures were used. The first, the Jacob-Munz Perceived Stress Index (PSI) (1968), is a checklist of 15 "feeling phrases." $\mathrm{S}$ was made familiar with the phrases in the preexperimental period. Four copies of the checklist were placed on a clipboard in front of the $S$, and he

Table 2

Mean Stress Intensity Scores and Standard Deviations (SD) for Each Stimulus Block for Each Condition on the PSI

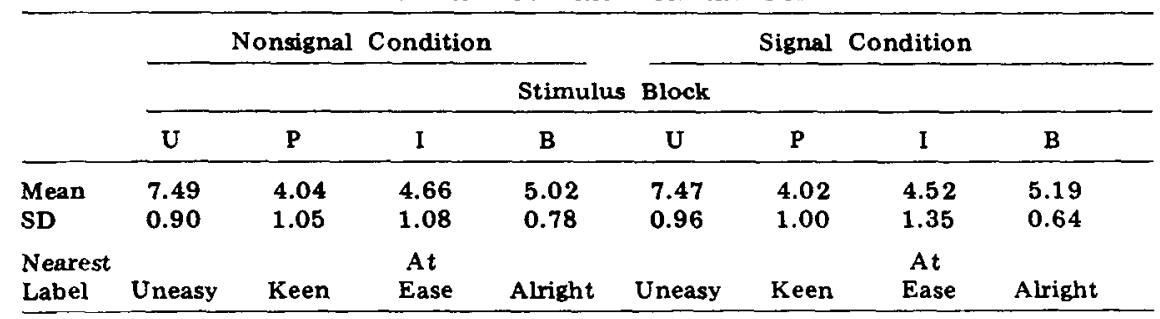




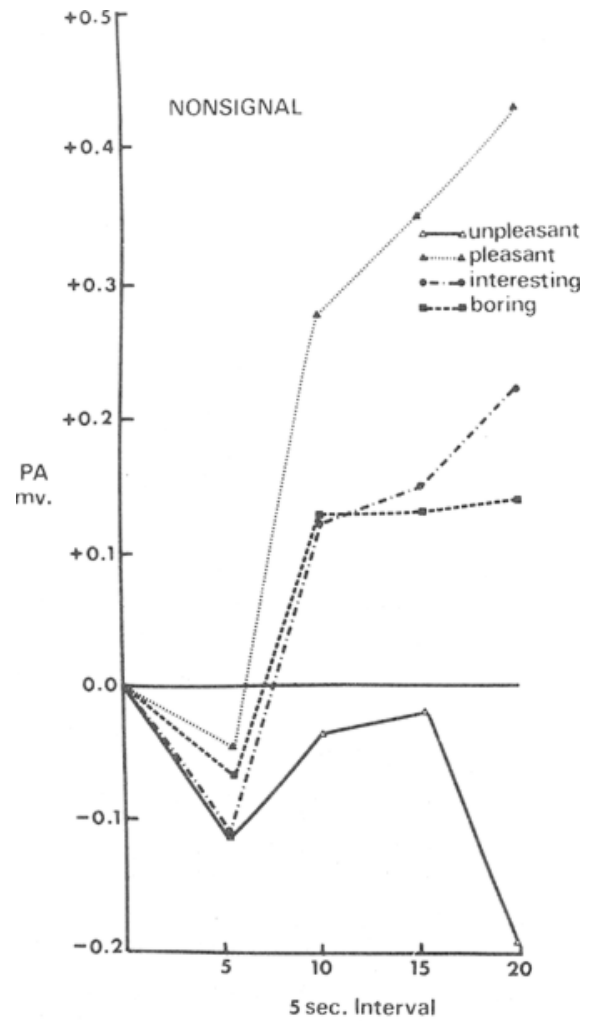

Fig. 1. Average forehead PA for each of the four 5-sec intervals of slide presentation meaned for each stimulus block.

was asked to check off the phrase which best described the way he felt during the preceding block of slides as a whole. This he had to do immediately after the block had been presented. The second self-report measure consisted of a larger group of 50 "feeling labels"--those classified by Davitz (1969). This was administered after all the slides had been presented. 2

During the preexperimental period, it was impressed upon $S s$ in the nonsignal group that this was not a memory task and that all they were required to do was to look at the slides. They were told that the first rating procedure involved only a gross general impression of how he felt during each block of slides and that for the second, more rigorous, rating procedure, $8 \times 10$ in. photographs of the slides would be provided as an aid. This maneuver, it was assumed, would reduce the signal value of the slides.

The Ss in the signal group were told that the task involved remembering the slides and that the postexperimental report would require reasonably complete recall of all 24 slides. They were not informed of the $8 \times 10$ in. photographs.

After the electrodes were attached, the $E$ spent about $10 \mathrm{~min}$ calibrating the recording apparatus. The $S$ was

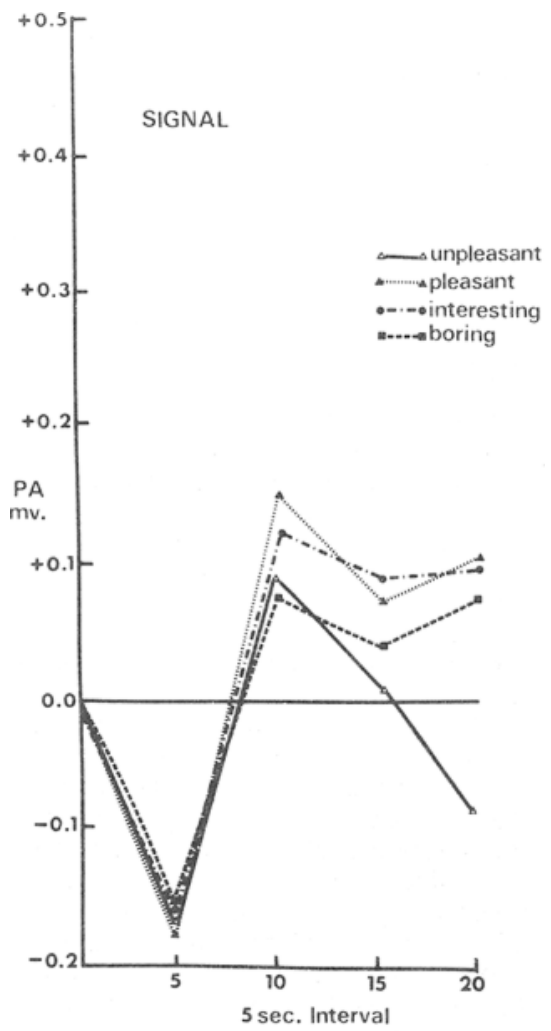

then instructed to relax and told that the first slide would appear in about $2 \mathrm{~min}$. At the end of the first block of slides, the $S$ was asked to make his rating on the PSI. This normally took about $20 \mathrm{sec}$. He was then told to relax and that the second block of slides would appear about $1.5 \mathrm{~min}$ later. This procedure was repeated until stimulus presentation was complete.
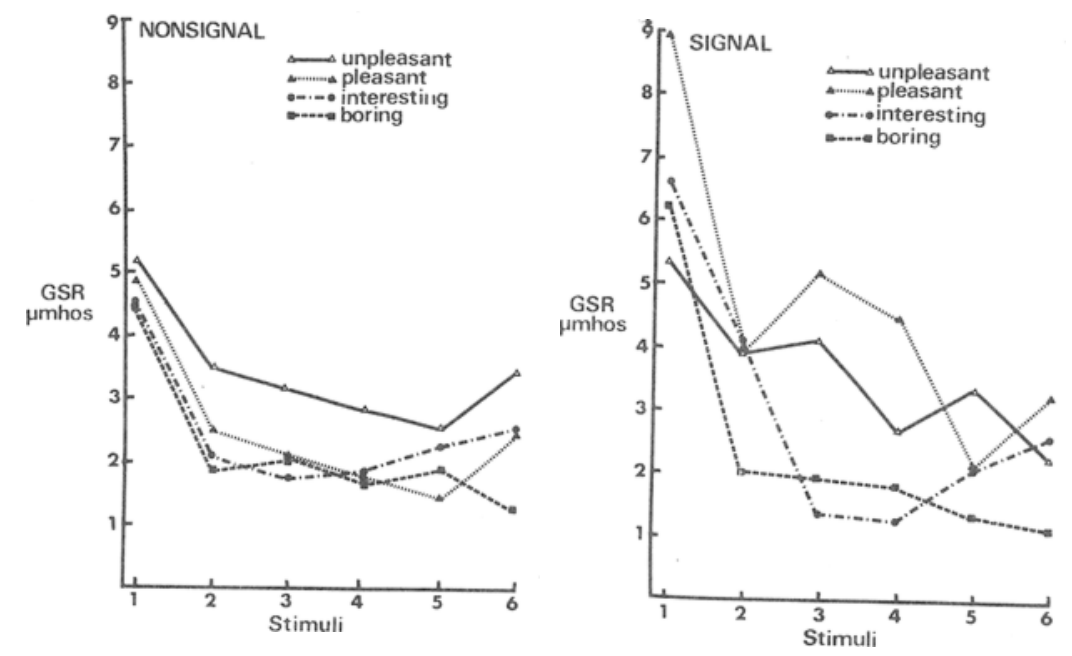

Fig. 2. Mean GSR for each slide, for both signal and nonsignal conditions.

\section{RESULTS}

Self-Report

The mean intensity score (with standard deviations) on the PSI for each slide block in both signal and nonsignal conditions is shown in Table 2. The "feeling label" nearest approximating to these scores is also represented.

Table 2 reveals the same array of PSI scores for the signal and nonsignal conditions.

\section{Forehead Pulse Amplitude}

A beat-by-beat analysis of PA was undertaken. The individual amplitude values were averaged in successive 5 -sec intervals for all the 20-sec stimulus presentation periods. These successive 5 -sec-interval mean values were then averaged over each stimulus block. Thus, for each stimulus block, four values were obtained: the first value indicating the mean PA during the first $5 \mathrm{sec}$ of presentation of the six slides in the block; the second indicating the mean $\mathrm{PA}$ during the second 5 sec; and so on. These block means were expressed as deviations (in millivolts) from the mean amplitude of the 10 pulses immediately preceding the onset of the particular stimulus block. Deviations below the prestimulus baseline amplitude were considered to indicate vasoconstriction. Deviations above the baseline were regarded as vasodilatory changes.

These PA changes for both signal and nonsignal conditions are represented in Fig. 1.

Analysis of variance (Winer, 1962) revealed a significant effect of signal and nonsignal value condition on PA $(F=5.90, \mathrm{df}=1 / 22, p<.025)$. The effects of stimulus block $(F=9.90$, df $=3 / 66, p<.001)$ and 5 -sec interval $(\mathrm{F}=63.73, \mathrm{df}=3 / 66, \mathrm{p}<.001)$ on 
PA were also significant. The analysis also revealed an interaction between signal nonsignal condition and stimulus block ( $F=3.44, \mathrm{df}=3 / 66$, $\mathrm{p}<.025$ ). The Stimulus Block by 5 -sec Interval interaction effect on PA was significant $(F=14.21, d f=9 / 198$, $\mathrm{p}<.001$ )

Galvanic Skin Response

The magnitude of the GSR to each stimulus was calculated as the difference between the skin conducted level just prior to the onset of each stimulus and the level attained immediately following stimulus onset. Only GSRs with a latency of less than 5 sec from stimulus onset were included. The mean GSR magnitude for each stimulus was computed for both signal and nonsignal conditions, and these values are plotted in Fig. 2.

Analysis of variance revealed no significant difference between signal and nonsignal conditions with respect to their effect on PA ( $F=0.53$, df $=1 / 22)$. Stimulus block $(F=3.57$, df $=3 / 66, \quad p<.025$ ) and stimulus position $(F=25.33, \mathrm{df}=5 / 10$, $\mathrm{p}<.001$ ) were found to significantly influence GSR magnitude.

$$
\text { DISCUSSION }
$$

The results indicate that the forehead PA response is sensitive to changes in signal value. The pattern of PA responses observed for the signal value condition in the present study is similar to those found by Hare et al (1970). This strongly suggests that the discrepancy between the findings of Hare et al (1970) and those of Carroll ${ }^{1}$ is due to signal value differences.

The general pattern of forehead PA responses was found to be more complex than that observed by Sokolor (1963) to simple auditory stimulation: Carroll ${ }^{1}$ and Hare et al
(1970) both noted initial forehead vasoconstriction with a variety of stimuli. In the present study, for both signal and nonsignal conditions, constriction was noted as the initial response to all stimuli.

GSR was found to be insensitive to changes in signal value, a result at odds with the findings of Cohen \& Johnson (1969). They found that signal value increased the resistance of the GSR to habituation. They also found that change in signal value did not influence the forehead PA response. Germana \& Chernault (1968), too, found that signal value investment increased the persistence of the GSR. However, Campos \& Johnson (1967) observed that instructions for later verbalization influenced heart-rate response but not skin conductance level.

It would appear that the actual means of conveying signal value on stimuli and the nature of the response demanded of $S s$ are critical determinants of the particular effects of signal value on physiological responding. The responses demanded of $\mathrm{Ss}$ in the Germana \& Chernault (1968) and the Cohen \& Johnson (1969) studies were well-defined motor responses. In the Campos \& Johnson (1967) study and the present study, the response demanded was not so clearly defined.

Self-report was not influenced by changes in signal value. The general insensitivity of self-report measures has been noted often (Mordkoff 1964; Weinstein, Averill, Opton, \& Lazarus, 1968).

\section{REFERENCES}

CAMPOS, J. J., \& JOHNSON, H. J. Affect, verbalization and directional fractionation of autonomic responses. Psychophysiology, 1967, 3, 285-290.

COHEN, M. J., \& JOHNSON, H. J. The effects of signal and non-signal stimuli on the orienting and defensive responses. Paper presented at the annual meeting of the Society for Psychophysiological Research, Monterey, California, October 1969.

DAVITZ, $\mathrm{J}, \mathrm{R}$. The language of emotion. New York: Academic Press, 1969

GERMANA, J., \&. CHERNAULT, G. Patterns of galvanic skin responses to signal and non-signal stimuli. Psychophysiology, 1969, 5, 28 4-292.

GRAHAM, F. K., \& CLIFTON, R. K. Heart rate change as a component of the orienting response. Psychological Bulletin, 1966, 65, 305-320.

HARE, R., WOOD, K., BRITAIN, $S_{n}$ \& SHADMAN, J. Autonomic responses to affective visual stimulation. Psychophysiology, 1970, 7, 408-417.

JACOBS, $P, D$., \& MUNZ, D. C. An index for measuring perceived stress in a college population. Journal of Psychology, 1968, $70,9-15$.

MORDKOFF, A. M. The relationship between psychological and physiological responses to stress. Psychosomatic Medicine, 1964, 26, 135-150.

ORNE, M. T. On the social psychology of the psychological experiment: With particular reference to demand characteristics and their implications. American Psychologist. 1962, 17. 776-783.

SOKOLOV, E. N. Perception and the conditioned reflex, Oxford: Pergamon Press, 1963

WEINSTEIN, J., AVERILL, J. R., OPTON, E. M., JR., \& LAZARUS, R. S. Defensive style and discrepancy between self-report and physiological indexes of stress. Journal of Personality \& Social Psychology, 1968, 10, 406-413.

WINER, B. J. Statistical principles in experimental design. New York: McGraw-Hill, 1962

\section{NOTES}

1. Carroll, D. Orienting and defensive responses to affective visual stimuli. Submitted for publication.

2. Although no further report of this measure is given here, it is being used by the author to assess the correlation between self-report and physiological response to the individual slides. 